\title{
Signaling of reactive oxygen and nitrogen species in diabetes mellitus
}

Igor Afanas'ev

Vitamin Research Institute; Moscow, Russia and Porto Portugal

Key words: reactive oxygen and nitrogen species, signaling, diabetes

Submitted: $10 / 20 / 10$

Revised: $11 / 26 / 10$

Accepted: 12/06/10

Previously published online: www.landesbioscience.com/journals/ oximed/article/14415

DOI: 10.4161/oxim.3.6.14415

Correspondence to: Igor Afanas'ev; Email: iafananizer@gmail.com
D isorder of physiological signaling functions of reactive oxygen species (ROS) superoxide and hydrogen peroxide and reactive nitrogen species (RNS) nitric oxide and peroxynitrite is an important feature of diabetes mellitus type 1 and type 2 . It is now known that hyperglycemic conditions of cells are associated with the enhanced levels of ROS mainly generated by mitochondria and NADPH oxidase. It has been established that ROS stimulate many enzymatic cascades under normal physiological conditions, but hyperglycemia causes ROS overproduction and the deregulation of ROS signaling pathways initiating the development of diabetes mellitus. On the other hand the deregulation of RNS signaling leads basically to a decrease in NO formation with subsequent damaging disorders. In the present work we will consider the pathological changes of ROS and RNS signaling in enzyme/gene regulated processes catalyzed by protein kinases $\mathrm{C}$ and $\mathrm{B}$ (Akt/B), phosphatidylinositol 3'-kinase (PI3-kinase), extracellular signal-regulated kinase 1/2 (ERK1/2) and some others. Furthermore we will discuss a particularly important role of several ROS-regulated genes and adapter proteins such as the p66shc, FOXO3a and Sirt2. The effects of low and high ROS levels in diabetes will be also considered. Thus the regulation of damaging ROS levels in diabetes by antioxidants and free radical scavengers must be one of promising treatment of this disease, however, because of the inability of traditional antioxidative vitamin $\mathrm{E}$ and $\mathrm{C}$ to interact with superoxide and hydrogen peroxide, new free radical scavengers such as flavonoids, quinones and synthetic mimetics of superoxide dismutase (SOD) should be intensively studied.

\section{Introduction}

Major reactive oxygen and nitrogen species (ROS and RNS) consist of paramagnetic free radicals (superoxide $\mathrm{O}_{2}{ }^{-}$, hydroxyl $\mathrm{HO}$, peroxy ROO and nitric oxide free radical (.)NO) and diamagnetic molecules (hydrogen peroxide $\mathrm{H}_{2} \mathrm{O}_{2}$ and peroxynitrite $\mathrm{ONOO}^{-}$) which are products of the reactions of these free radicals. All these species were previously considered to be toxic agents capable of damaging biomolecules. However it is now known that physiological free radicals superoxide and nitric oxide are relatively harmless species but are able to initiate or mediate many enzyme- and gene-depended reactions in both physiological and pathophysiological processes. Increasing evidences of experimental and clinical studies suggest that ROS play important role in the pathogenesis of both diabetes type 1 (characterized by body's failure to produce insulin) and diabetes type 2 (developed due to insulin resistance when cells fail to use insulin properly). ${ }^{1}$ Bashan et al. ${ }^{2}$ demonstrated numerous examples of free radical formation and participation in diabetes 1 and 2 and following complications such as cardiovascular disease, diabetic retinopathy, nephropathy and others. These authors also stressed that free radicals and ROS may participate in normal physiological process of insulin activation as well as in the initiation of numerous pathological disorders. Pitocco et al. ${ }^{3}$ recently discussed the role of oxidative stress in the pathogenesis of insulin resistance and beta-cell dysfunction. We now suggest that it is possible to investigate separately "normal" 
and defective ROS signaling pathways in various pathologies including diabetes mellitus in order to develop new methods of the suppression of damaging ROS signaling.

\section{Sources of Reactive Oxygen Species in Diabetes Mellitus}

As the development of diabetes mellitus is characterized by high levels of glucose, this prooxidant molecule can be an origin of ROS overproduction. High glucose (HG) can initiate the production of superoxide and hydrogen peroxide, precursors of reactive free radicals, which are able to stimulate the decline of antioxidant systems, directly damage many biomolecules, increase lipid peroxidation and develop the insulin resistance in diabetes. For example Graier et al. ${ }^{4}$ proposed that HG can induce superoxide formation in aortic endothelial cells through metal-mediated oxidation. Du et $a .^{5}$ showed that the incubation of human endothelial cells (HUVEC) with high glucose led to rapid increase in ROS formation, the activation of nuclear factor $\mathrm{NF \kappa B}$, the induction of apoptosis and $\mathrm{NO}$ synthase uncoupling by a glucose-specific mechanism. They also suggested that peroxynitrite can be a mediator of the cytotoxic effects of high glucose in endothelial cells.

HG stimulated a sharp increase in vascular superoxide and a 50\% reduction in $\mathrm{Na}^{+} \mathrm{K}^{+}$-ATPase activity in rabbit aorta. ${ }^{6}$ Superoxide production was inhibited by $\mathrm{L}$-arginine and stimulated by $\mathrm{N}-\omega$-nitro$\mathrm{L}$-arginine that pointed out at the participation of uncoupling $\mathrm{NO}$ synthases. Mullarkey et al. ${ }^{7}$ showed that glycated proteins enhanced superoxide production and lipid peroxidation comparing to non-glycated proteins suggesting that increasing glycation of proteins may accelerate lipid damage in diabetes.

However subsequent studies showed that the most important sources of ROS under hyperglycemic conditions are mitochondria and NADPH oxidases. Hyperglycemia decreased glyceraldehyde3-phosphate dehydrogenase (GAPDH) activity in bovine aortic endothelial cells via the increased production of mitochondrial superoxide and a concomitant increase in hexosamine pathway activity. ${ }^{8,9}$ Leloup et al. $^{10}$ showed that glucose-induced mitochondrial ROS production can stimulate insulin secretion in isolated rat islets. They found that glucose increased about threefold ROS generation that was highly correlated with insulin secretion. Mitochondrial origin of ROS was proved by the stimulatory effects of mitochondrial blockers antimycin and rotenone. Altogether, these findings demonstrated that mitochondrial ROS production was an important stimulus for glucose-induced insulin secretion.

Munusamy and MacMillan-Crow proposed that HG-stimulated generation of mitochondrial superoxide led to mitochondrial injury in renal proximal tubular cells. ${ }^{11} \mathrm{HG}$ induced superoxide generation and hyperpolarization in mitochondria, followed by secondary events, a decline in ATP levels, partial Complex III inactivation and loss of cell viability. Coughlan et al. ${ }^{12}$ showed that in diabetic nephropathy advanced glycation end-products (AGEs) enhanced the formation of cytosolic ROS which accelerated mitochondrial superoxide production. Taken together, these findings suggested that the AGE-induced cytosolic ROS production facilitated mitochondrial superoxide production in hyperglycemic environments. It has been recently confirmed that AGEs form at an accelerated rate under diabetes and play a role in diabetic nephropathy through ROS generation. ${ }^{13}$

Bindokas et al..$^{14}$ measured the rates of mitochondrial superoxide generation in rat isolated islets in response to glucose. Superoxide content of isolated islets was increased with glucose stimulation. These authors suggested that overproduction of superoxide was associated with perturbed mitochondrial morphology.

As it follows from the above, glucosestimulated ROS production is considered by many authors as a one of the major ways of ROS formation in diabetes; however contradictory data have been received in several works. Martens et al. ${ }^{15}$ found that glucose suppressed mitochondrial superoxide formation in metabolically responsive pancreatic beta cells. In addition to the suppression of hydrogen peroxide and superoxide formation, glucose increased cellular NADPH and NADH levels. Furthermore the high rates of glucose metabolism did not increased ROS levels in primary $\beta$-cells but actually prevented the accumulation of superoxide. This effect was highest in $\beta$-cells with a higher metabolic responsiveness to glucose. Mitochondrial nutrients reduced superoxide formation.

Mitochondrial ROS have also been implicated in diabetic complications and progression of the underlying diabetic state; however, it is not clear whether mitochondria of diabetic origin really generate ROS independently of the surrounding diabetic milieu. Herlein et al. ${ }^{16}$ showed that the gastrocnemius, heart and liver mitochondria of streptozotocin diabetic rats were not irrevocably altered to produce excess superoxide either by complex I or complex III. Moreover, gastrocnemius and heart mitochondria demonstrated an increase and not decrease in respiratory coupling. In addition, mitochondria of insulin-deficient diabetic rats did show the signs of ROS overproduction.

NADPH oxidases are another important ROS source in diabetes. In 2002 Guzik et al. ${ }^{17}$ showed that superoxide production significantly increased by upregulated NADPH oxidase and endothelial NO synthase in human blood vessels from patients with diabetes type 2 . These effects of NADPH oxidase and uncoupling eNOS might be mediated by protein kinase C (PKC) signaling. Leehey et al. ${ }^{18}$ demonstrated that HG increased superoxide production in human mesangial cells through angiotensin II (Ang II)-NADH/ NADPH oxidase cascade. Yang et al. ${ }^{19}$ also showed that insulin stimulated NADPH oxidase activity and superoxide production in Ang II-treated rat vascular smooth muscle cells (VSMCs) causing increased cell migration. Jeong et al. ${ }^{20}$ assumed that the enhanced proliferative capacity of diabetic VSMC is a consequence of NADPH oxidase activation stimulated by the activation of a protein tyrosine kinase. Gupte et al. ${ }^{21}$ found that the expression and activity of glucose-6-phosphate dehydrogenase (G6PD) was enhanced in the liver of diabetic Zucker obese fa/fa rats that led to the activation of NADPH oxidase and superoxide generation. G6PD activity was regulated by phosphatidylinositol 3-kinase (PI3K)/tyrosine kinase ( $\mathrm{Src}$ ) signaling pathways. 
On the other hand Gao and Mann suggested that ROS formation by HG-stimulated NADPH oxidase can also upregulate antioxidant enzymes. ${ }^{22}$ Therefore NADPH oxidase might be double-edged sword phenomenon providing a feedback defense against excessive ROS generation through the activation of receptor tyrosine kinases and the redoxsensitive transcription factor Nrf2-Keap1 signaling pathway. It is of importance that Block et al. ${ }^{23}$ have recently identified NADPH oxidase (Nox4) as mitochondrial cytochrome $c$ oxidase subunit IV being the additional source of ROS in diabetes. It should be noted that xanthine oxidase (XO) is also a potential source of ROS formation in diabetes. Matsumoto et al. ${ }^{24}$ showed that plasma XO activity increased 3-fold in diabetic mice two weeks after the onset of diabetes, as compared with control mice.

Now we can present principal sources of ROS production in diabetes mellitus (Figs. 1 and 2). There are numerous data which demonstrate mitochondria ROS overproduction (first of all superoxide) in diabetes and diabetic complications although it is difficult to identify the exact sites of ROS formation in mitochondria. Earlier works (for example, Du et al.5) apparently suggested that glucose can directly stimulates ROS overproduction, but it has been shown later that HG activates various enzymatic cascades in mitochondria, the activation of NADPH oxidase, uncoupling of $\mathrm{NO}$ synthases and the activation of xanthine oxidase. .,9-15,18-24 $^{-1}$ Glycated proteins can also be the promoters of ROS formation. ${ }^{7}$

Thus different sources are apparently responsible for ROS overproduction (oxidative stress) in diabetes. For some time mitochondria was considered a major source of ROS overproduction in diabetes and diabetic complications. However, Martens et al. ${ }^{15}$ demonstrated that HG might actually suppressed mitochondrial superoxide formation in metabolically responsive pancreatic $\beta$-cells. Similarly, Herlein et al. ${ }^{16}$ showed that there was no excess superoxide production by complexes I and III from mitochondria of streptozotocin diabetic rats. Thus mitochondrial ROS production in diabetes should be farther thoroughly re-investigated.

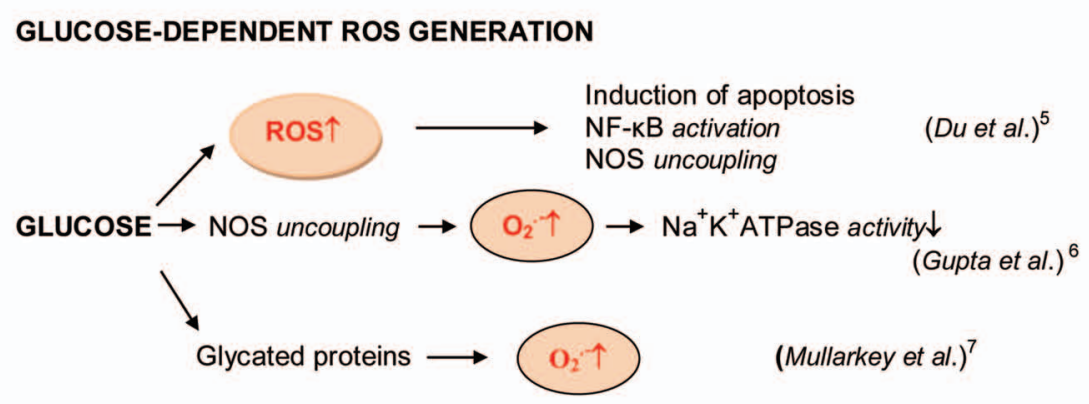

MITOCHONDRIAL SUPEROXIDE PRODUCTION IN DIABETES

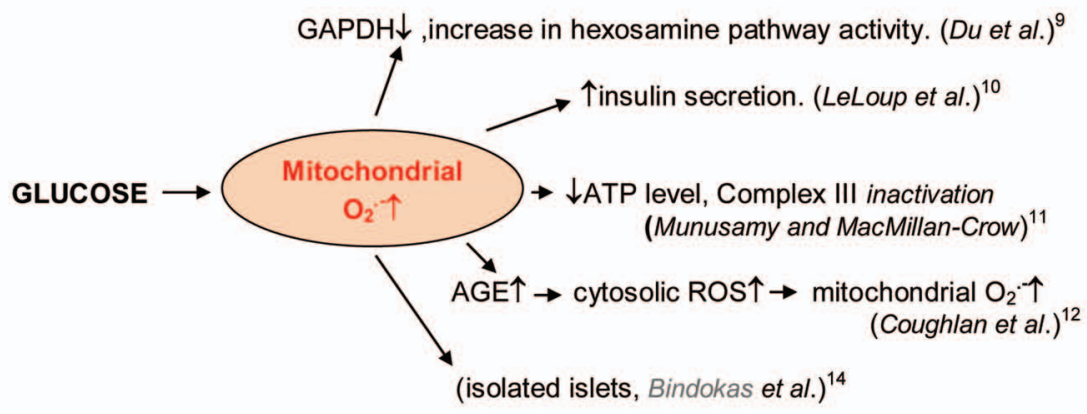

MITOCHONDRIA DOES NOT ENHANCE SUPEROXIDE PRODUCTION

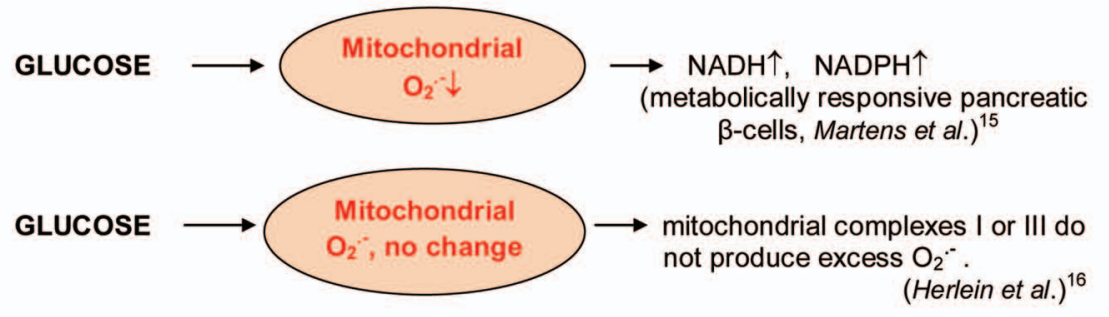

Figure 1. Induction of ROS formation by glucose in diabetes. Glucose enhanced ROS formation that induced apoptosis through the nuclear factor NFKB activation and NOS uncoupling in human endothelial cells. ${ }^{5}$ Hyperglycemia increased endothelial superoxide that impaired smooth muscle cell $\mathrm{Na}^{+}-\mathrm{K}^{+}$-ATPase activity. ${ }^{6}$ Glucose enhanced the formation of glycated proteins and superoxide formation. ${ }^{7}$ Mitochondrial superoxide production in diabetes. Glucose stimulated superoxide formation in diabetic mitochondria. ${ }^{9-12,14}$ Glucose decreased or was not changed mitochondrial superoxide formations..$^{15,16}$

In confirmation to findings obtained by Martens et al. ${ }^{15}$ Hou et al. ${ }^{25}$ also observed the significant ROS generation under low glucose conditions in mouse $\beta$-cell, which was prevented by the ROS scavengers $\mathrm{N}$-acetylcysteine (NAC) and manganese(III)tetrakis(4-benzoic acid) porphyrin. Disagreement of these works (reviewed in ref. 15, 16 and 25) with other numerous opposite data is difficult to explain.

\section{ROS Overproduction is an Origin of Harmful Signaling in Diabetes and Diabetic Complications}

Protein kinases $\mathrm{C}$ and Akt/B, extracellular signal-regulated kinases ERK1/2, p38 kinase, c-Jun N-terminated kinases, phosphatases and many other enzymes are regulated by ROS under normal physiological conditions. ${ }^{26}$ However ROS overproduction can also alter normal enzymatic 


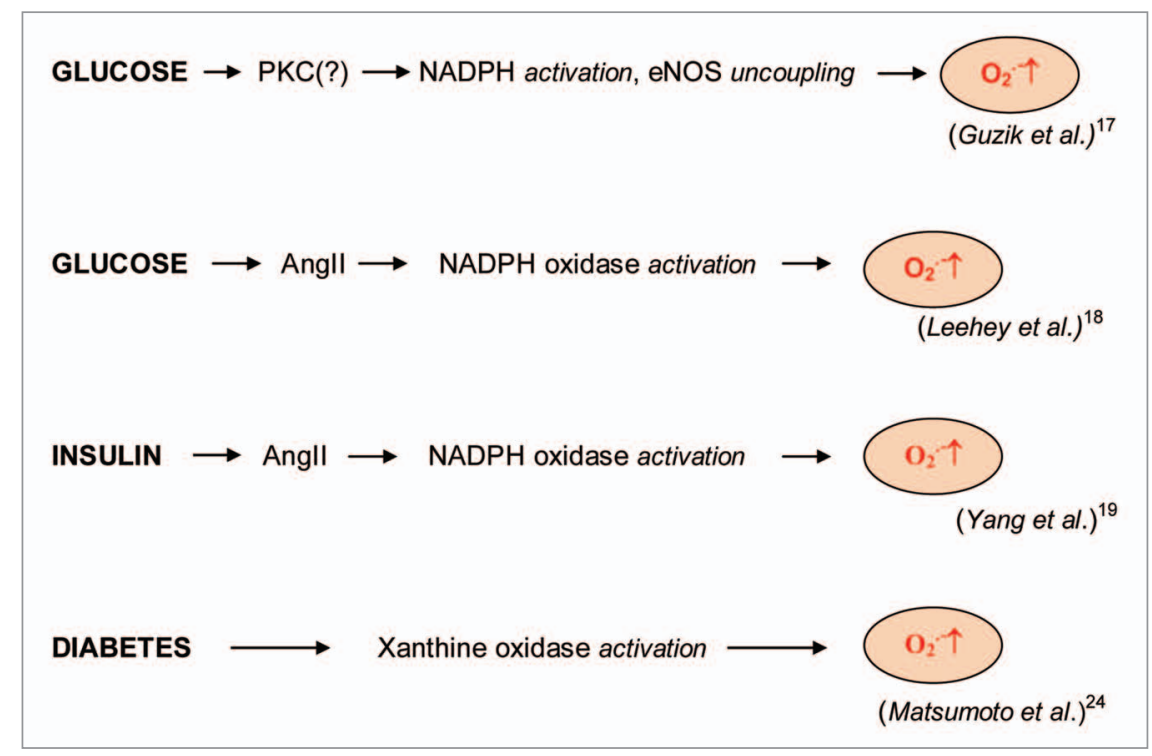

Figure 2. Glucose-stimulated superoxide formation catalyzed by NADPH oxidase in diabetes. ${ }^{17,18}$ Insulin-stimulated superoxide formation catalyzed by NADPH oxidase in diabetes. ${ }^{19}$ Superoxide production catalyzed by xanthine oxidase. ${ }^{24}$

cascades and initiate pathological disorders. Damaging effects of superoxide and hydrogen peroxide, the precursors of reactive free radicals are well recognized. However the direct attack of reactive free radicals ( $\mathrm{HO}$ and $\mathrm{ROO}$ ) on biomolecules which was earlier regarded as an only pathway of free radical-mediated damage in biological systems might be less important than the changes in enzymatic processes induced by ROS overproduction.

Protein kinases catalyze the reactions of lipid hydrolysis and phosphorylation of various substrates and enzymes; however, as it has recently been shown, these heterolytic processes can be initiated by ROS (reviewed in ref. 26). It is important to understand how ROS signaling in normal physiological processes can be transformed into damaging enzyme-catalyzed pathways. Interesting observation has been made by Cao et al. ${ }^{27}$ who studied the inhibition of tumor carcinogenesis by synthetic retinoid N-(4-hydroxyphenyl) retinamide (4-HPR). They suggested that 4-HPR-mediated ROS formation changed the Akt-catalyzed surviving cascade in cancer cells into apoptotic one by the Akt conformational change through the formation of an intramolecular disulfide bond. This study shows that ROS can initiate the transformation of enzymatic cascades.
A major source of ROS-initiated harmful transformation must be ROS overproduction due to appearing of some new prooxidant factors. Such factors appear under hyperglycemic conditions. It is known that the ROS activation of protein kinase C (PKC) stimulates subsequent ROS overproduction; therefore this enzymatic cascade can be an important harmful signaling process in hyperglycemia and diabetes. Thus, In 1998 Koya and King suggested that the glucose adverse effects in diabetes and hyperglycemia might be a consequence of ROS-stimulated activation of diacylglycerol (DAG)/PKC enzymatic pathway because the treatment with $\alpha$-tocopherol prevented glucose-induced vascular dysfunctions and inhibited DAG/ PKC activation. ${ }^{28}$ Geolotto et al. ${ }^{29}$ studied the effect of insulin on ROS formation and the stimulation of PKC-dependent enzymatic cascade in cultured skin fibroblasts from human volunteers. They found that insulin induced translocation of the p 47 (phox) subunit of NADPH oxidase from the cytosol to the membrane and ROS formation through a PKC- $\delta$ dependent mechanism. It was proposed that insulin activated phosphatidylinositol 3-kinase (PI3K), PKC- $\delta$, p47(phox) translocation and ERK1/2 phosphorylation.

Lee et al..$^{30}$ hypothesized that high glucose induced the activation of PKC in human peritoneal mesothelial cells (HPMC) and increased ROS formation which, in turn, activated PKC and induced glucose-depended fibronectin upregulation in HPMC. Xia et al. ${ }^{31}$ demonstrated that HG stimulated vascular endothelial growth factor (VEGF) expression in rat mesangial cells through NADPH oxidasedepended ROS formation and the activation of PKC- $\beta(1)$ and PKC- $\zeta$ isoenzymes. In subsequent work Xia et al. ${ }^{32}$ showed that the very early responses of mesangial cells to HG included the transforming growth factor TGF $\beta$ (1) stimulation of PKC isoenzymes, PI3K-depended activation of PKC- $\zeta$ and following generation of ROS by NADPH oxidase.

Angiotensin-converting enzyme ACE2 is a major ANG(1-7)-generating enzyme in vascular smooth muscle cells (VSMCs), and its expression is decreased by prolonged exposure to glucose. It has been shown that ANG(1-7) treatment prevented the development of cardiovascular complications in rat diabetic animal models. ${ }^{33}$ It was also demonstrated that glycotoxin-induced NADPH oxidase (Nox1) expression was regulated by conventional PKCs. Surprisingly Nox1-derived superoxide reduced PKC- $\beta$ II expression that lowered ACE2 mRNA and protein levels and consequently decreases ANG(1-7) formation. Some examples of ROS signaling in harmful enzymatic cascades catalyzed by PKCs in hyperglycemia and diabetes are presented in Figure 3.

ROS signaling is also an important stimulus of harmful enzymatic cascades catalyzed by protein kinase Akt/B. Ceolotto et al. ${ }^{34}$ showed that insulin significantly increased production of intracellular superoxide in human fibroblasts and that its effect was completely abolished by the superoxide scavengers Tyron and the cell-permeable superoxide dismutase mimetic as well as by the inhibitor of NADPH oxidase apocynin but not by rotenone or oxypurinol. Inhibition of PI3K pathway also blocked insulin-stimulated superoxide production. It has been suggested that elevated insulin activated PI3K/Akt pathway which stimulated $\mathrm{NADPH}$ oxidase-depended superoxide production through the phosphorylation and translocation of its $\mathrm{p} 47 \mathrm{phos}$ component from the cytosol to the membrane. 
Superoxide in turn induced the phosphorylation and activation of ERK1/2 MAPKs (Fig. 3).

Kinoshita et al. ${ }^{35}$ also demonstrated that high glucose activated the PI3K/ Akt pathway and stimulated NADPH oxidase-depended superoxide formation resulting in the superoxide-induced impairment of ATP-sensitive $\mathrm{K}^{+}$channel in the human visceral artery. Simone et al. ${ }^{36}$ investigated the mechanisms of oxidative DNA damage in the rat model of type 1 diabetes, in murine proximal tubular epithelial cells and rat proximal tubular epithelial cells. They found an increase in Akt phosphorylation which was associated with enhanced phosphorylation of tumor suppressor tuberin, decreased 8-oxo-7,8-dihydro2'-deoxyguanosine (8-oxodG) levels and 8-oxoG-DNA glycosylase (OGG1) protein expression. Exposure of epithelial cells to high glucose caused the rapid increase in ROS formation which correlated with an increase in the Akt and tuberin phosphorylation. Inhibition of PI3K/Akt pathway significantly reduced HG-induced tuberin phosphorylation and restored OGG1 expression. NAC inhibited ROS generation and Akt phosphorylation and decreased 8-oxodG accumulation and upregulation of OGG1 protein expression. These findings suggested that hyperglycemia in diabetes type 1 led to the phosphorylation/inactivation of tuberin and downregulation of OGG1 via ROS-dependent activation of Akt. This signaling cascade provides the mechanism of oxidative stress-mediated DNA damage in diabetes.

Allen and Bayraktutan studied the effects of hyperglycemic insult on human brain microvascular endothelial cells (HBMEC) and human astrocytes. ${ }^{37}$ Hyperglycemia induced significant increase in the blood-brain barrier $(\mathrm{BBB})$ permeability that was reversed by glucose normalization. Antioxidants (ascorbic acid, free radical scavengers, antioxidative enzymes catalase and superoxide dismutase mimetics) attenuated HG detrimental effects. It was found that glucose-depended ROS induced BBB hyperpermeability by activation of p38 mitogen-activated protein kinase and PKC.

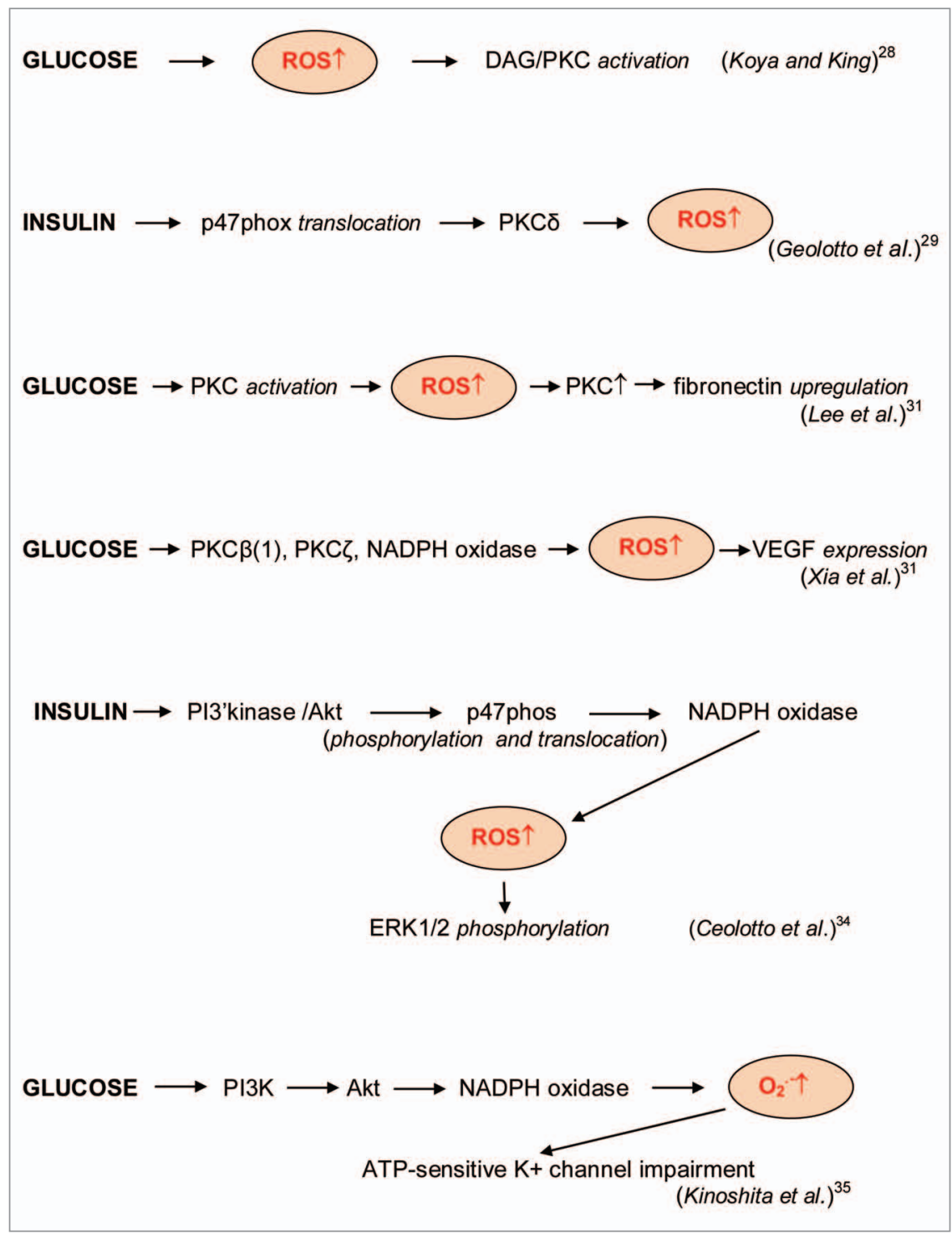

Figure 3. Protein kinases in enzymatic cascades of ROS signaling in diabetes. Glucose and insulin stimulated the enhanced ROS formation in enzymatic cascades with activation of diacylglycerol (DAG)/protein kinase $C(P K C)$, protein kinase $C \delta$, protein kinases $C \beta(1)$, protein kinase $C \zeta$, protein kinase B/Akt and phosphatidylinositol 3-kinase/protein kinase B (PIK/Akt). ${ }^{28-31,34,35}$

Li et al..$^{38}$ showed that aorta from streptozotocin-(STZ)-induced diabetic rats and vascular smooth muscle cells (VSMC) exposed to high glucose exhibited the decreased levels of guanine nucleotidebinding proteins (Gi $\alpha$ proteins). They found that the decreased HG-induced levels of Gi $\alpha$ proteins depended on ROS overproduction that was inhibited by SOD mimetic MnTBAP, uric acid (scavenger of peroxynitrite) and $\mathrm{N}(6)$-nitro-L-arginine methylester (L-NAME, an inhibitor of NO synthase) but not catalase. Thus, in this case an enhanced oxidative stress was apparently depended on the augmented levels of peroxynitrite but not hydrogen peroxide.

Shen et al. ${ }^{39}$ showed that high glucose upregulated Rac1, a small signaling $G$ protein and NADPH oxidase and induced cardiomyocyte apoptosis. In type 2 diabetic $d b / d b$ mice, the administration of Rac1 inhibitor NSC23766 significantly inhibited NADPH oxidase activity and apoptosis and slightly improved myocardial function. Therefore Rac1 is a possible mediator of hyperglycemia-induced apoptosis in cardiomyocytes and its effect might depend on NADPH oxidase activation and mitochondrial ROS generation. Lin et al. ${ }^{40}$ found that 


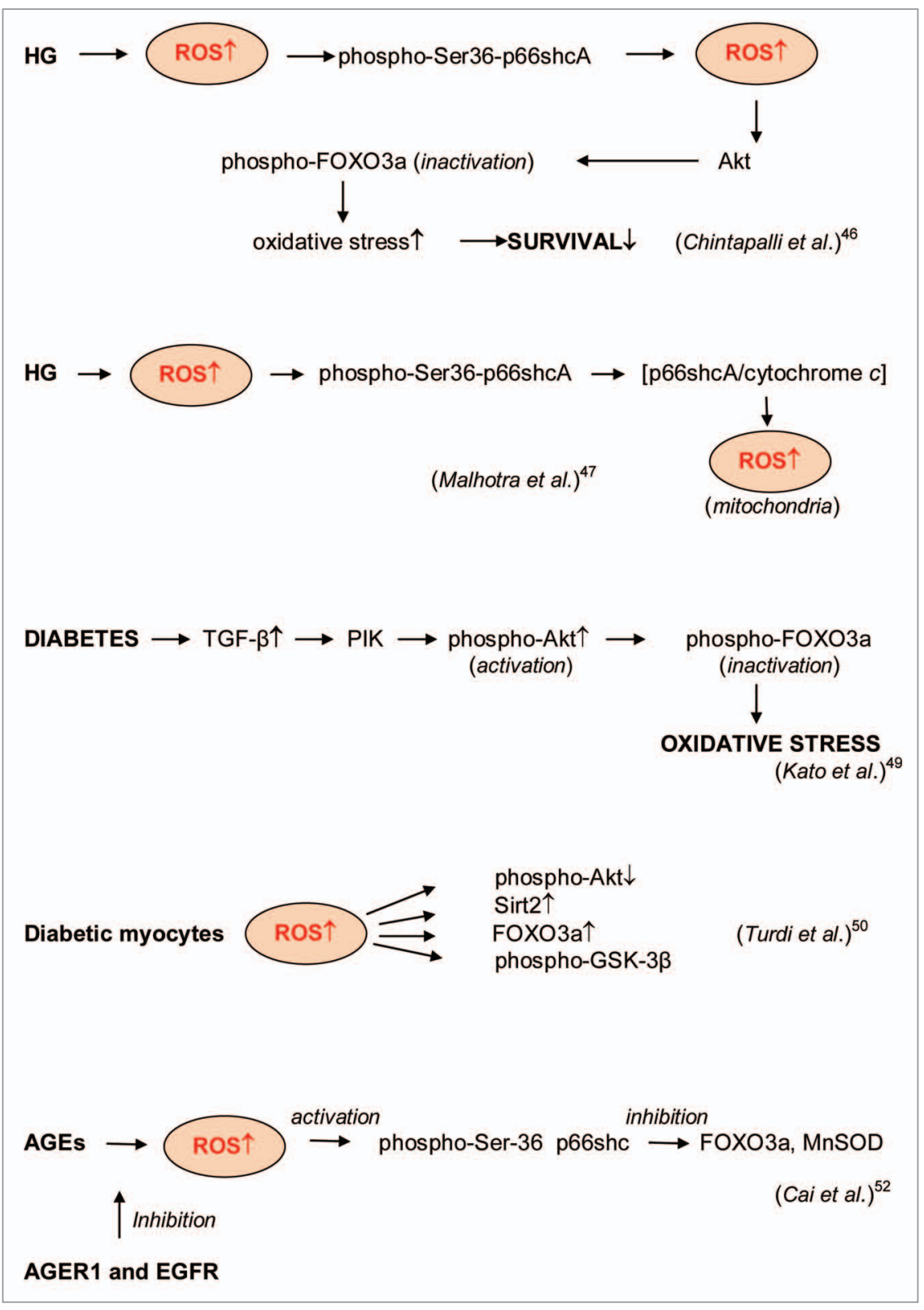

Figure 4. ROS signaling in enzyme/gene-depended processes. High glucose (HG)-induced ROS formation resulted in the phosphorylation of Ser36-p66shcA protein that promoted further ROS formation. ROS overproduction activated Akt/PKB kinase, which phosphorylated and inactivated FOXO3a protein, enhanced oxidative stress and suppressed the survival phenotype. ${ }^{46,47}$ Diabetes increased the levels of transforming growth factor TGF $\beta$ that led to the inactivation of phosphoFOXO3a protein and the enhanced oxidative stress. ${ }^{49}$ Enhanced ROS in diabetic myocytes caused upregulation of the silent information regulator 2 (Sirt2) and FOXO3a, the reduction of Akt phosphorylation and the phosphorylation of glycogen synthase kinase GSK-3 $\beta .^{50}$ The advanced glycation end products (AGEs) promoted the Ser-36 phosphorylation of p66shc, FOXO3a inactivation and MnSOD suppression in a ROS-dependent manner. This pathway can be blocked by AGER1 (an AGE-receptor that counteracts receptor for advanced glycation end products RAGE) and epidermal growth factor receptor (EGFR). ${ }^{52}$

Ras ( $\mathrm{G}$ protein) induced superoxide formation but not that of nitric oxide or hydrogen peroxide in HG- and AGE-stimulated activation of ERK, p38 and c-Jun kinases in rat glomerular mesangial cells. effects of hyperglycemia. Ceolotto et al. ${ }^{41}$ showed that rosiglitazone (RSG), a drug for the treatment of patients with type 2 diabetes inhibited phosphorylated AMPK and suppressed NADPH oxidase activation during glucose-induced oxidative stress. In addition RSG inhibited PKC. These findings suggested that RSG protected endothelial cells against glucoseinduced ROS overproduction through an AMPK-dependent and a PPAR $y$ (the peroxisome proliferator-activated receptor)independent mechanism. Similarly Eid et al. ${ }^{42}$ showed that the activation of AMPK blocked HG-induced expression of Nox4, Nox4-depended ROS generation and apoptosis of glomerular epithelial cells (podocytes).

\section{ROS Signaling in the Enzyme/ gene Cascades Under Hyperglycemic Conditions}

Gene/enzymatic processes play important role in development of diabetes. It has been shown that several genes participate in the regulation of ROS-depended enzyme/ gene cascades in hyperglycemia and diabetes among them $p 66 s h c$ gene encoding the p66shc adaptor protein, $F O X O 3 a$ gene encoding the FOXO3a protein and the gene family SIRTUIN encoding silent information regulator Sirtuin (human Sirt1 and Sirt3 and yeast Sir2) proteins. It should be mentioned that these genes also regulate many ROS-depended processes in aging, cancer and other pathologies.

p66shc protein presents in both mitochondria and cytosol but only in mitochondria this protein is activated by ROS through phosphorylation of the critical serine residue Ser-36. ${ }^{43}$ In 1999 Migliaccio et $\mathrm{al}^{44}$ showed that targeted mutation of the mouse $p 66 s h c$ gene induced stress resistance and prolonged lifespan in experimental animals. For example p $66 \mathrm{shc}^{-1-}$ mice increased resistance to oxidative stress and had a 30\% increase in lifespan. Therefore the activation of p66shc is expected to stimulate the ROS harmful effects. Camici et al. ${ }^{45}$ compared p66 $\left(\mathrm{shc}^{-/}\right)$and wild-type (WT) mice which were made diabetic by an injection of streptozotocin. Streptozotocin-treated p66 $\left(\mathrm{shc}^{-/}\right)$and WT mice showed a similar increase in blood glucose but significant 
differences with respect to endothelial dysfunction and oxidative stress. WT diabetic mice displayed marked impairment of endothelium-dependent relaxations, increased peroxynitrite generation, nitrotyrosine expression and lipid peroxidation. In contrast, p66( $\left.\mathrm{shc}^{-/}\right)$diabetic mice did not develop these HG-mediated abnormalities. Furthermore, protein expression of antioxidant enzyme heme oxygenase 1 and endothelial NO synthase were upregulated in p66 $\left(\mathrm{shc}^{-/}\right)$but not in WT mice. In addition $\mathrm{p} 66\left(\mathrm{shc}^{-/-}\right)$mice were resistant to HG-induced, ROS-dependent endothelial dysfunction.

Chintapalli et al. ${ }^{46}$ proposed that ROS induced phosphorylation of p66shcA protein at the critical $\mathrm{CH} 2-S e r-36$ residue and that the phosphorylated protein promoted further the intracellular generation of ROS. ROS overproduction activated Akt/PKB kinase, which phosphorylated and inactivated FOXO3a protein (Fig. 4). By this way $\mathrm{HG}$ can induce oxidative stress and depress the survival phenotype. Malhotra et al. $^{47}$ confirmed that HG-stimulated ROS induced phosphorylation of the Ser36 residue of p66shcA that caused the collapse of mitochondrial transmembrane potential and the formation of p66shcA/ cytochrome- $c$ complexes. These authors suggested that p66shcA is a molecular redox switch responsible for the enhancement of mitochondrial ROS generation.

Diabetic cardiomyopathy is one of major complications of diabetes. Rota et al. ${ }^{48}$ showed that diabetes stimulated premature myocyte senescence and death, which together resulted in the development of cardiac myopathy. They demonstrated that the ablation of p66shc had remarkable beneficial consequences on the viability and function of cardiac progenitor cells in p66 $\left(\mathrm{shc}^{-/-}\right)$mice.

FOXO3a belongs to the $\mathrm{O}$ subclass of the forkhead family of transcription factors which are characterized by a fork head DNA binding domain. There are three main proteins FOXO1, FOXO3a and FOXO4 from which the FOXO3a protein is considered to be a regulator of longevity and cancer. It was found that the phosphorylation of p66shc stimulated ROS formation, the phosphorylation of FOXO3a and the development of oxidative stress (Fig. 4).
It has been shown that the levels of transforming growth factor TGF $\beta$ were enhanced in mesangial cell (MC) under diabetic conditions and in diabetic nephropathy that led to the activation of the PI3K/Akt pathway. ${ }^{49}$ It was also proposed that the phosphorylation-mediated inactivation of transcription factor FOXO3a by TGF $\beta$ increased survival. These findings suggest that Akt/FOXO3a pathway might be a mechanism by which TGF $\beta$ can strengthen oxidative stress in early diabetic nephropathy, thereby accelerating renal disease.

Turdi et al. ${ }^{50}$ demonstrated the participation of the silent information regulator 2 (Sirt2) and upregulated FOXO3a in cardiomyocyte dysfunction from diabetes mice. It was found that diabetes enhanced ROS, reduced Akt phosphorylation, enhanced Sirt 2 level and upregulated FOXO3a as well as the phosphorylation of glycogen synthase kinase GSK-3 $\beta$. Catalase significantly decreased diabetes-induced changes in phospho-Akt, FOXO3a and Sirt2 (Fig. 4). Davila and Torres-Aleman showed that ROS overproduction killed neurons by stimulating FOXO3 whose activity was inhibited by insulin-like growth factor I (IGF-I). ${ }^{51}$ They observed the activation of $\mathrm{FOXO} 3$ by hydrogen peroxide in neurons firstly through Akt inhibition and p38 MAPKmediated blockade of IGF-I and secondly through the FOXO3 activation by Junkinase 2 (JNK2).

As it was noted above, the advanced glycation end products (AGEs) are another origin of ROS in diabetes. Cai et al. ${ }^{52}$ showed that AGEs promoted the Ser36 phosphorylation of p66shc and FOXO inactivation in a ROS-dependent manner. AGE-induced ROS mediated early changes in the p66shc signaling pathway and also stimulated prolonged suppression of MnSOD. This pathway can be blocked by AGER1 (an AGE-receptor that counteracts receptor for advanced glycation end products RAGE) and epidermal growth factor receptor (EGFR) and might probably be a novel mechanism by which AGER1 promotes antioxidant homeostasis (Fig. 4).

The important role of $\mathrm{FOXO} 3$ and Sirt1 has also been confirmed in recent works. Hou et al. ${ }^{53}$ demonstrated that the presence of FoxO3a was critical for early apoptotic membrane signaling and subsequent degradation of nuclear DNA in diabetic cells. Maiese et al. ${ }^{54}$ suggested that targeting FoxO proteins could be a novel therapeutic strategy for the treatment of diabetes and other deadly diseases. For this purpose the members of Foxo family together with the growth factor and cytokine erythropoietin (EPO) might be applied..$^{556}$ Avogaro et al. ${ }^{57}$ commented that decreased NAD-dependent activity of Sir1 may mediate the shortened lifespan in conditions of insulin resistance.

\section{ROS Signaling in Insulin/insulin Receptor/insulin Receptor Substrate Cascade}

Under physiological conditions insulin transmits signals through a complicated signaling cascade which includes insulin or insulin-like growth factor (IGF-1), insulin receptor (IR), insulin receptor substrate 1 (IRS-1) and PIK/Akt or ERK kinases. ROS overproduction can disturb this process at different stages inducing insulin resistance in diabetes type 2 or enhancing insulin signals. The effects of ROS on insulin signaling were demonstrated in various cells and under the stimulation by different prooxidant agents.

It has been shown that protein tyrosine phosphatases (PTPs) are quickly inactivated by superoxide and hydrogen peroxide. (Both ROSs are able to oxidize sulfhydryl groups of phosphatase cysteines but superoxide is a more effective species). ${ }^{26,58,59}$ PTPs normally serve as negative regulators for insulin action through the dephosphorylation of the insulin receptor and its phosphorylated cellular substrates. However, ROS can effectively block their activity and reverse their inhibitory effects on insulin signaling.

The inhibition of PTPs resulted in the activation of IR tyrosine kinase and reduced insulin resistance. ${ }^{60} \mathrm{Wu}$ et al. ${ }^{61}$ showed that the phosphorylation of the insulin receptor, IRS-1 and Akt in response to insulin was significantly enhanced in high glucose, especially at insulin submaximal concentrations. In primary rat adipocytes, high glucose increased insulin-stimulated hydrogen peroxide production and stimulated the 


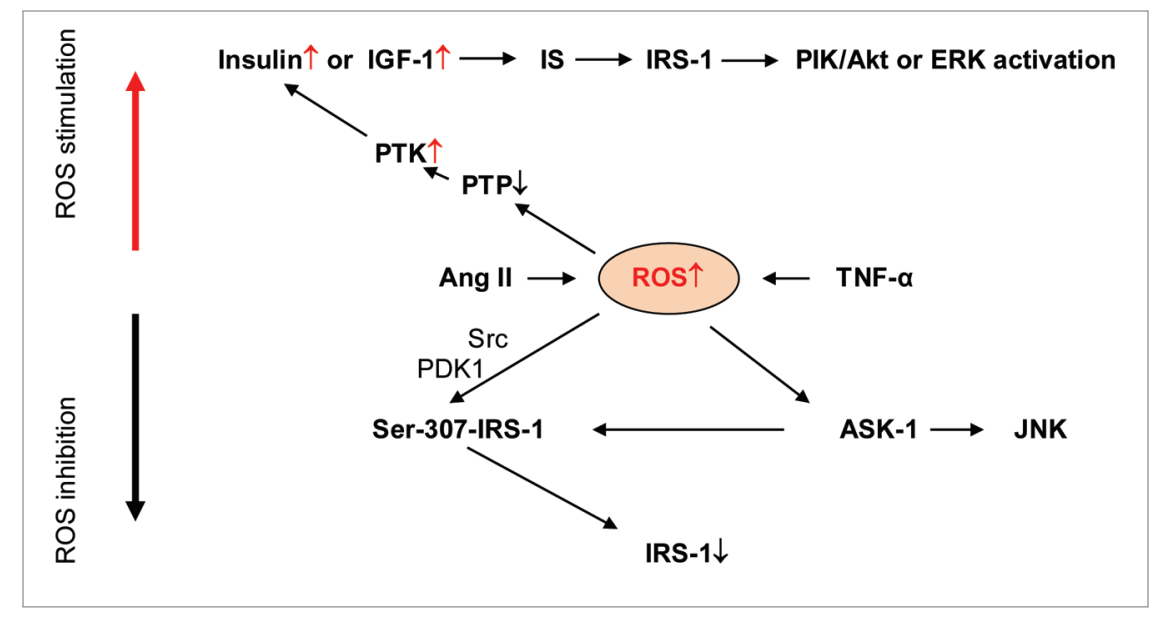

Figure 5. ROS signaling in insulin/insulin receptor/insulin receptor substrate cascade. ROS overproduction in diabetes can be induced by tumor necrosis factor-alpha TNF $\alpha$ or angiotensin II. Enhanced levels of ROS causes the inhibition of protein tyrosine phosphatase (PTP) and activation of IR tyrosine kinase that stimulates insulin transmitted signals included insulin or insulin-like growth factor (IGF-1), insulin receptor (IR), insulin receptor substrate 1 (IRS-1) and PIK/Akt or ERK kinases. On the other hand ROS-depended activation of tyrosine kinase Src, phosphoinositide-dependent kinase-1 PDK1 and phosphorylation of IRS-1 on Ser-307 causes IRS-1 degradation.

inhibition of PTPs. Droge pointed out that the activity of basal insulin receptor tyrosine kinase was strongly increased by small concentrations of hydrogen peroxide or by the oxidation of the intracellular sulfhydryl residues. ${ }^{62}$ However, prolonged exposure to hydrogen peroxide inhibited insulin action suggesting that insulin signaling was enhanced only in moderate oxidative conditions and inhibited by excessive exposure to hydrogen peroxide (Fig. 5). Meng et al. ${ }^{63}$ showed that insulin stimulation induced rapid oxidation and inactivation of tyrosine phosphatase PTP1B.

To ascertain the effect of ROS on liver regeneration and underlying signaling pathways, Beyer et al. ${ }^{64}$ studied liver repair in mice lacking the Nrf2 transcription factor. In hepatocytes of these animals ROS induced insulin/insulin-like growth factor resistance and reduced the expression of several antioxidant enzymes. The deficiency of Nrf2 impaired the activation of p38 MAPK and Akt kinases resulting in the enhanced death and delayed proliferation of hepatocytes.

In addition to inhibition of tyrosine phosphatases (favorable effect on insulin signaling) ROS are able to negatively influence IRS-1 activation. Taniyama et al. ${ }^{65}$ showed that angiotensin II decreases IRS-1 protein levels in vascular smooth muscle cells through tyrosine kinase Src, phosphoinositide-dependent kinase-1
PDK1 and ROS-mediated phosphorylation of IRS-1 on Ser-307. Ser-307IRS-1phosphorylation, which caused subsequent IRS-1 degradation, was stimulated by angiotensin II and was blocked by the Src inhibitor PP1 and the antioxidants $N$-acetylcysteine and ebselen.

Imoto et al. ${ }^{66}$ investigated the role of $\mathrm{TNF} \alpha$ in impaired insulin signaling. They found that mitochondria could be a source of TNF $\alpha$-induced ROS production in cells, and therefore mitochondrial ROS can contribute to pathogenesis of TNF $\alpha$ induced insulin resistance. It was also showed that mitochondrial ROS production by TNF $\alpha$ stimulated ASK1 (apoptosis signal-regulating kinase 1) and JNK activation. It was also demonstrated that TNF $\alpha / R O S$-initiated cascade increased Ser-307 phosphorylation of insulin receptor substrate 1 (IRS-1) and decreased its insulin-stimulated tyrosine phosphorylation. All these effects are believed to be molecular basis of TNF $\alpha$-induced insulin resistance. ${ }^{67}$

It has been already mentioned that oxidative stress is a double-edged phenomenon: the moderate ROS overproduction can enhance insulin signaling while strong ROS overproduction can be destructive. ${ }^{62}$ This might be well explained by the different effects of ROS inhibition on PTPs and phosphorylation of Ser-307-IRS-1 (Fig. 5). Whereas the oxidation of sulfhydryl groups of PTPs by ROS stimulated the activation of insulin receptor protein tyrosine kinase PTK and enhanced insulin signaling, ROS phosphorylation of Ser307-IRS-1led to the inhibition of IRS-1.

\section{ROS Signaling in Glucose-induced Insulin Secretion}

Pancreatic $\beta$-cells exposed to hyperglycemia produce ROS which can suppress glucose-induced insulin secretion (GIIS). Sakai et al ${ }^{68}$ suggested that high glucose induced mitochondrial ROS, which suppressed the first-phase of GIIS through the inhibition of glyceraldehyde 3-phosphate dehydrogenase (GAPDH) activity. Krauss et al. ${ }^{69}$ demonstrated that endogenously produced mitochondrial superoxide activated uncoupling protein 2 (UCP2)-mediated proton leak, thus lowering ATP levels and impairing GIIS. Pi et al. ${ }^{70}$ pointed out that $\beta$-cells manifested relatively low expression of many antioxidant enzymes. This made these cells susceptible to ROS-induced damage but at the same time may also stimulate ROS signaling. They suggested that insulin secretion might be stimulated by HG-induced hydrogen peroxide. Leloup et al. ${ }^{10}$ also showed that mitochondrial ROS production was necessary for glucose-induced insulin secretion. However, strong oxidative stress might be damaging for insulin secretion. Thus Li et al. ${ }^{71}$ 
demonstrated that the secretory response to $15 \mathrm{~mm}$ glucose was reduced by $40 \%$ in rat islets or cells stressed 3 days. It was also proposed that ROS-mediated GIIS might in turn lead to further increasing ROS production. $^{72}$

\section{ROS Signaling in Insulin Resistance}

ROS overproduction is an important trigger for insulin resistance, an important factor of diabetes type 2 development. ${ }^{73}$ Again, mitochondria and NADPH oxidase are considered the major sources of ROS overproduction. Mitochondrial superoxide production is a common feature of many models of insulin resistance in adipocytes, myotubes and mice. Hoehn et al. ${ }^{74}$ demonstrated that insulin resistance reversed upon exposure to mitochondrial uncouplers or MnSOD mimetics. In addition, antimycin $\mathrm{A}$, the complex III antagonist, which increased mitochondrial superoxide production, caused rapid attenuation of insulin action. These findings confirm the ability of mitochondrial superoxide to be a promoter of insulin resistance.

Nakamura et al. ${ }^{75}$ found that palmitate, but not the unsaturated fatty acid oleate stimulated mitochondrial ROS production, which inhibited the insulininduced tyrosine phosphorylation of insulin receptor substrate 2 (IRS-2) and the serine phosphorylation of Akt through JNK activation enhancing insulin resistance in hepatocytes. The ROS/JNK/ CREB(transcription factor)/PGC- $1 \alpha$ (peroxisome proliferator-activated receptor- $\gamma$ coactivator $1 \alpha$ ) pathway was at least partly involved in the pathogenesis of liver insulin resistance. Kumashiro et al. ${ }^{76}$ found that ROS induced phosphorylation of CREB, and it may be a common signal pathway in different kinds of cells. Decrease in ROS levels in liver might be potentially effective strategy to improve insulin resistance due to the ability of ROS activated JNK which at least partly was the origin of hepatic insulin resistance. In addition the reduction of ROS formation increased phosphorylation and expression of insulin receptor substrate 1 (IRS-1) through the reduction of JNK activity.
Ali et al. ${ }^{77}$ investigated insulin resistance and the role of protein tyrosine phosphatase PTP1B in impaired $\mathrm{NO}$-mediated dilation in obesity. It is known that the insulin receptor is a classic receptor tyrosine kinase which is inhibited by protein tyrosine phosphatase PTP1B. These authors found that obese mouse was insulin-resistant and had tissue-specific elevation in PTP1B expression compared to lean controls. PTP1B deletion improved glucose clearance, dyslipidemia and insulin receptor signaling in muscle and fat. Additionally, the impairment in obese mice correlated with increased superoxide and was corrected by superoxide scavengers. Increased superoxide production was associated with increased expression of NADPH oxidase. Deletion of PTP1B improved both endothelium-dependent and endothelium-independent NO-mediated dilation and reduced superoxide generation in obese mice. Taken together, these data show importance of peripheral insulin resistance in vascular dysfunction in obesity.

\section{RNS Signaling in Diabetes}

Nitric oxide is the endothelium-derived relaxing factor (EDRF) and its role is very important in the normal activity of cells. Therefore, it might be expected that similarly to the other pathological states a decrease in NO can take place in diabetes. On the other hand, nitric oxide can manifest damaging activity through the rapid interaction with superoxide to form reactive peroxynitrite. Therefore the uncoupling NO synthases might increase superoxide and peroxynitrite formation. Thus Langenstroer and Pieper found that spontaneous EDRF released in diabetic rat aorta can be unmasked by the addition of SOD because SOD produced a significantly greater relaxation in diabetic aorta compared to control aorta. ${ }^{78}$ It means that NO synthases in diabetes produce superoxide in uncoupled state. Other authors (Reviwed in ref. 5,6 and 17) also suggested that peroxynitrite formed by uncoupled NO synthases in human blood vessels from patients with diabetes type 2 can be a mediator of the cytotoxic effects of high glucose.
Dixon et al. ${ }^{79}$ studied the enhanced platelet superoxide production induced by endothelial NO synthase uncoupled in patients with hypertension alone and in patients with coexistent diabetes. Superoxide production was significantly higher in patients with diabetes and hypertension than in patients with hypertension. After incorporation of $N$-nitroL-arginine methyl ester hydrochloride (L-NAME), superoxide levels increased in both patients with diabetes and hypertension and in patients with hypertension. It might be explained by the suppression of peroxynitrite formation. These findings suggest that eNOS can reside in the uncoupled state in patients with hypertension and, to a greater extent, in patients with coexisting hypertension and diabetes.

Oak and Cai found that angiotensin II induced uncoupling of endothelial $\mathrm{NO}$ synthase to produce superoxide in aortic endothelial cells. ${ }^{80}$ They showed that streptozotocin-induced diabetic mice had a marked increase in aortic superoxide production, which was inhibited by the eNOS inhibitor L-NAME. Ang II receptor type 1 blocker candesartan or ACE inhibitor captopril decreased eNOSderived superoxide and hydrogen peroxide production. Racl-dependent NADPH oxidase activity was more than doubled in the endothelium-denuded diabetic aortas but was attenuated by candesartan or captopril, indicating that NADPH oxidase remained active in non-endothelial vascular tissues, although uncoupled eNOS was at least partly responsible for endothelial superoxide production.

Thum et al. ${ }^{81}$ showed that uncoupling of endothelial NO synthase took place in diabetic bone marrow, glucose-treated endothelial progenitor cells (EPCs) and EPCs from diabetic patients resulting in eNOS-mediated superoxide production. EPC dysfunction was mediated by protein kinase $\mathrm{C}$ and was associated with reduced intracellular $\mathrm{BH} 4$ (tetrahydrobiopterin) concentrations. Subsequent decrease in EPC levels and the impairment of EPC function may contribute to the pathogenesis of vascular disease in diabetes.

Huang et al. ${ }^{82}$ studied the role of ROS and $\mathrm{NO}$ in the stimulation by advanced glycation end products (AGE) of renal tubular hypertrophy in diabetic 
nephropathy (DN). They found that AGE (but not nonglycated bovine serum albumin) significantly suppressed the $\mathrm{NO} / \mathrm{cGMP} / \mathrm{PKG}$ signaling in human renal proximal tubular cells. NO donors $S$-nitroso-N-acetylpenicillamine (SNAP), sodium nitroprusside (SNP) and antioxidants NAC and taurine significantly suppressed the AGE inhibition of NO production. Russo et al. ${ }^{83}$ proposed that the NO/cGMP/cGMP-dependent protein kinase (PKG) pathway in vascular smooth muscle cells (VSMCs) from obese rats was impaired apparently due to enhanced ROS formation.

It is known that high glucose triggers endothelial cell apoptosis by the inactivation of endothelial nitric oxide synthase (eNOS). At the same time it has been found that the interaction of eNOS with heat shock protein 90 (HSP90) and Akt and the phosphorylation of eNOS were upregulated by high glucose exposure in human umbilical vein endothelial cells (HUVEC) for 2-4 h. ${ }^{84}$ Therefore it was proposed that during early phase of high glucose exposure, apoptosis can be prevented by the enhancement of eNOS activity, the augmentation of eNOS/ HSP90 interaction and Akt activation. It is of interest that hyperthermia can decrease eNOS uncoupling under hyperglycemic conditions by the enhancement of eNOS/HSP90 interaction and increasing NO production. ${ }^{85}$

\section{ROS Overproduction in Diabetes and Antioxidant Treatment}

The above experimental findings show that the signaling function of overproduced ROS in numerous enzyme/gene pathways is an important factor of diabetes development. In spite of some contradictory data hyperglycemia is most certainly a major source of ROS overproduction. Recently Turan discussed the application of various antioxidants for the suppression of damaging ROS overproduction in diabetes. ${ }^{86} \mathrm{~A}$ main difficulty in determination of damaging effects of free radicals in diabetes is the ROS and RNS participation in too many enzymatic and gene cascades where they frequently reveal conflicting actions. It is now well known that the major signaling free radicals superoxide and nitric oxide are practically harmless species and cannot directly damage biomolecules, but they can be converted in reactive hydroxyl and peroxy free radicals through the Fenton reaction or recombine to form peroxynitrite. Damaging effects of reactive radicals can be neutralized by traditional antioxidants (free radical scavengers) ascorbic acid or $\alpha$-tocopherol.

However, the disturbance of physiological signaling processes mediated by superoxide, nitric oxide and hydrogen peroxide which takes place under pathological conditions such as diabetes mellitus is probably a much more important damaging factor. Aforementioned data demonstrate the transformation of normal ROS signaling into damaging cascades under hyperglycemic conditions. Figures 2-5 show many enzymatic and gene-mediated pathways by which hyperglycemia stimulate ROS harmful signaling.

Unfortunately (or fortunately) ROS signaling can initiate both favorable and unfavorable enzymatic/gene processes. It has been demonstrated above that low ROS levels might stimulate favorable changes in diabetic enzymatic pathways. For example Goldstein et al. ${ }^{60}$ showed that the inhibition of PTPs resulted in the activation of IR tyrosine kinase and reduced insulin resistance. Droge pointed out that the small concentrations of hydrogen peroxide increased the activity of basal insulin receptor tyrosine kinase. ${ }^{62}$ Leloup et al. ${ }^{10}$ also showed that mitochondrial ROS production was necessary for glucose-induced insulin secretion. Gao and Mann proposed that ROS formed by HG-stimulated NADPH oxidase might also upregulate antioxidant enzymes. ${ }^{22}$ Therefore NADPH oxidase can be considered as a double-edged sword enzyme providing a feedback defense against excessive ROS generation.

If the effects of ROS signaling in enzyme/gene processes depend on the levels of ROS production, then ROSinduced damage in diabetes (as well in the other pathologies such as cardiovascular diseases, inflammation, aging, etc.,) cannot be successfully inhibited by traditional antioxidants ascorbic acid (vitamin C) or $\alpha$-tocopherol (vitamin E) which are unable to react with superoxide. . $^{87,88}$ Nonetheless some aforementioned data demonstrate the successful application of various antioxidants and free radical scavengers for suppression of damaging processes in diabetes. For example Allen and Bayraktutan showed that ascorbic acid, free radical scavengers, catalase and superoxide dismutase mimetics diminished the detrimental effects of high glucose. ${ }^{37}$ Koya and King found that $\alpha$-tocopherol prevented many glucose-induced vascular dysfunctions and inhibited DAG/PKC activation. ${ }^{28}$ Ceolotto et al. ${ }^{34}$ showed that the superoxide scavengers Tyron and cellpermeable superoxide dismutase mimetic completely inhibited insulin-stimulated superoxide production in human fibroblasts. These authors also demonstrated that rosiglitazone applied for the treatment of patients with type 2 diabetes inhibited phosphorylated AMPK and suppressed NADPH oxidase activation during glucose-induced oxidative stress while pravastatin inhibited ROS production by inhibiting PKC $\delta$ in human skin fibroblasts. ${ }^{41,89}$ Midaoui and Champlain showed that the application of antioxidant lipoic acid resulted in the prevention of development of oxidative stress and hypertension in diabetic models of insulin resistance. ${ }^{90}$ Schafer et al..${ }^{91}$ found that the selective mineralocorticoid receptor antagonist eplerenone suppressed aortic superoxide production in diabetic rats.

Mechanism of inhibitory activity of the above compounds is in many cases uncertain because only superoxide mimetics, flavonoids and quinones can directly react with superoxide. (Just recently Chacko et al. ${ }^{92}$ demonstrated that mitochondria-targeted ubiquinone (MitoQ) can ameliorate kidney damage in the mouse model (Akita mice) of type 1 diabetes).

It is probably more important that some enzyme inhibitors or promoters may favorably affect superoxide signaling. ${ }^{41,89,91}$ Bulhak et al. ${ }^{93}$ studied the application of peroxisome proliferator-activated receptor- $\alpha$ (PPAR- $\alpha$ ) for cardioprotection in type 2 diabetic rats. They found that that PPAR- $\alpha$ activation protected the type 2 diabetic rat myocardium against ischemia-reperfusion injury via the activation of PI3K/Akt and NO pathways. Calorie restriction $(\mathrm{CR})$ is a widely used treatment of experimental animals for the suppression of ROS overproduction and the 
enlargement of lifespan. Minamiyama et al. ${ }^{94}$ suggested that $\mathrm{CR}$ might show a beneficial effect in diabetic rats. They indeed found that CR significantly improved the NO-cGMP pathway through normalizing ROS generation. CR also prevented the ROS-induced damage of cardiovascular tissues provoked by diabetes mellitus.

\section{Discussion}

Present findings demonstrate importance of ROS and RNS signaling in many enzymatic cascades regulating the development of diabetes 1 and 2. It might also be suggested that the deregulation of ROS signaling is probably the beginning of pathological changes in diabetes. Among many damaging enzymatic pathways initiated by high glucose the processes regulated by p66shc and FOXO3a adaptive proteins are of special importance. These proteins are expressed by p66shc and $\mathrm{FOXO} 3 a$ genes, which are in turn stimulated by ROS. Willcox et al..$^{95}$ proposed that $F O X O 3 a$ phenotype is associated with a longer life in humans while the ROS-mediated phosphorylation of Ser-36-FOXO3a inactivated this process. ROS activates the p66shc protein through the phosphorylation of its Ser-36 residue leading to the activation of various kinases and further increase in mitochondrial ROS production (Fig. 4). Phosphorylation induces the inhibition of $\mathrm{FOXO} 3$ a activity and the activation of p66shc resulting in the enhancement of ROS signaling and diabetes development. Damaging effects of p66shc and FOXO3a might be suppressed by the regulation of their genes.

Another important member of signaling cascades is the protein kinase $\mathrm{B}$ (Akt). It has been demonstrated that the activation of PI3K/Akt pathway stimulated NADPH oxidase-depended superoxide production and DNA damage. ${ }^{34-36}$ On the other hand ROS overproduction can inhibit Akt.. ${ }^{50}$ (Fig. 4) Bulhak et al. ${ }^{93}$ also showed that PPAR- $\alpha$ activation protected the type 2 diabetic rat myocardium against ischemia-reperfusion injury via the activation of PI3K/Akt and NO pathways. Thus Akt kinase might participate in ROS-mediated cascades both as positive and negative factor of diabetes development.
Recent work by Hsu and Meng points out at important positive role of $\mathrm{NO}$ signaling in diabetes. ${ }^{96}$ These authors proposed that nitric oxide can enhance insulin responsiveness through the inactivation of protein-tyrosine phosphatases. It has also been shown that proto-oncogene protein Wnt-land cyclic adenosine monophosphate (cAMP) play important role in the regulation of oxidative stress under pathological conditions. ${ }^{97,98}$

\section{Conclusions}

Investigation of ROS signaling in enzymatic cascades which are responsible for developing diabetes type 1 and type 2 could be a fascinating task promising the discovery of new pharmaceutical agents and methods for the treatment of these pathologies. Aforementioned findings suggest the potential usefulness of the inhibitors of ROS signaling in gene/ enzymatic processes for the treatment of diabetes type 1 and type 2 .

\section{References}

1. Maritim AC, Sanders RA, Watkins JB, 3rd. Diabetes, oxidative stress and antioxidants: a review. J Biochem Mol Toxicol 2003; 17:24-38

2. Bashan N, Kovsan J, Kachko I, Ovadia H, Rudich A. Positive and negative regulation of insulin signaling by reactive oxygen and nitrogen species. Physiol Rev 2009; 89:27-71.

3. Pitocco D, Zaccardi F, Di Stasio E, Romitelli F, Santini SA, Zuppi C, Ghirlanda G. Oxidative stress, nitric oxide and diabetes. Rev Diabet Stud 2010 7:15-25.

4. Graier WF, Simecek S, Kukovetz WR, Kostner GM. High D-glucose-induced changes in endothelial $\mathrm{Ca}^{2+} /$ EDRF signaling are due to generation of superoxide anions. Diabetes 1996; 45:1386-95.

5. Du X, Stocklauser-Farber K, Rosen P. Generation of reactive oxygen intermediates, activation of NFkappaB and induction of apoptosis in human endothelial cells by glucose: role of nitric oxide synthase? Free Radic Biol Med 1999; 27:752-63.

6. Gupta S, Chough E, Daley J, Oates P, Tornheim K, Ruderman NB, et al. Hyperglycemia increases endothelial superoxide that impairs smooth muscle cell $\mathrm{Na}^{+}-\mathrm{K}^{+}$-ATPase activity. Am J Physiol Cell Physiol 2002; 282:560-6.

7. Mullarkey CJ, Edelstein D, Brownee M. Free radical generation by early glycation products: a mechanism for accelerated atherogenesis. in diabetes. Biochem Biophys Res Commun 1990; 173:932-9.

8. Nishikawa T, Edelstein D, Du XL, Yamagishi S, Matsumura T, Kaneda Y, et al. Normalizing mitochondrial superoxide production blocks three pathways of hyperglycaemic damage. Nature 2000; 404:787-90.

9. Du XL, Edelstein D, Rossetti L, Fantus IG, Goldberg $\mathrm{H}$, Ziyadeh F, et al. Hyperglycemia-induced mitochondrial superoxide overproduction activates the hexosamine pathway and induces plasminogen activator inhibitor-1 expression by increasing $\mathrm{Sp} 1 \mathrm{glyco}-$ sylation. Proc Natl Acad Sci USA 2000; 97:1222-6.
10. LeLoup C, Tourrel-Cuzin C, Magnan C, Karaca M, Castel J, Carneiro L, et al. Mitochondrial reactive oxygen species are obligatory signals for glucoseinduced insulin secretion. Diabetes 2009; 58:673-81.

11. Munusamy S, MacMillan-Crow LA. Mitochondrial superoxide plays a crucial role in the development of mitochondrial dysfunction during high glucose exposure in rat renal proximal tubular cells. Free Radic Biol Med 2009; 46:1149-57.

12. Coughlan MT, Thorburn DR, Penfold SA, Laskowski A, Harcourt BE, Sourris KC, et al. RAGE-induced cytosolic ROS promote mitochondrial superoxide generation in diabetes. J Am Soc Nephrol 2009; 20:742-52.

13. Yamagishi S, Matsui T. Advanced glycation end products, oxidative stress and diabetic nephropathy. Oxid Med Cell Longev 2010; 3:101-8.

14. Bindokas VP, Kuznetsov A, Sreenan S, Polonsky KS, Roe MW, Philipson LH. Visualizing superoxide production in normal and diabetic rat islets of Langerhans. J Biol Chem 2003; 278:9796-801.

15. Martens GA, Cai Y, Hinke S, Stange G, Van de Casteele M, Pipeleers D. Glucose suppresses superoxide generation in metabolically responsive pancreatic beta cells. J Biol Chem 2005; 280:20389-96.

16. Herlein JA, Fink BD, O'Malley Y, Sivitz WI Superoxide and respiratory coupling in mitochondria of insulin-deficient diabetic rats. Endocrinology 2009; 150:46-55.

17. Guzik TJ, Mussa S, Gastaldi D, Sadowski J, Ratnatunga C, Pillai R, et al. Mechanisms of increased vascular superoxide production in human diabetes mellitus: role of $\mathrm{NAD}(\mathrm{P}) \mathrm{H}$ oxidase and endothelial nitric oxide synthase. Circulation 2002; 105:1656-62.

18. Leehey DJ, Isreb MA, Marcic S, Singh AK, Singh R. Effect of high glucose on superoxide in human mesangial cells: role of angiotensin II. Nephron Exp Nephrol 2005; 100:46-53.

19. Yang M, Foster E, Kahn AM. Insulin-stimulated $\mathrm{NAD}(\mathrm{P}) \mathrm{H}$ oxidase activity increases migration of cultured vascular smooth muscle cells. Am J Hypertens 2005; 18:1329-34.

20. Jeong HY, Son SM, Kim YK, Yun MR, Lee SM, Kim CD. Tyrosine kinase-mediated activation of $\mathrm{NAD}(\mathrm{P}) \mathrm{H}$ oxidase enhances proliferative capacity of diabetic vascular smooth muscle cells. Life Sci 2005; $76: 1747-57$.

21. Gupte RS, Floyd BC, Kozicky M, George S, Ungvari ZI, Neito V, et al. Synergistic activation of glucose6-phosphate dehydrogenase and $\mathrm{NAD}(\mathrm{P}) \mathrm{H}$ oxidase by $\mathrm{Src}$ kinase elevates superoxide in type 2 diabetic, Zucker fa/fa, rat liver. Free Radic Biol Med 2009; 47:219-28

22. Gao L, Mann GE. Vascular NAD(P)H oxidase activation in diabetes: a double-edged sword in redox signalling. Cardiovasc Res 2009; 82:9-20.

23. Block K, Gorin Y, Abboud HE. Subcellular localization of Nox4 and regulation in diabetes. Proc Natl Acad Sci USA 2009; 106:14385-90.

24. Matsumoto S, Koshiishi I, Inoguchi T, Niwata H, Utsumi H. Confirmation of superoxide generation via xanthine oxidase in streptozotocin-induced diabetic mice. Free Radic Res 2003; 37:767-72.

25. Hou N, Torii S, Saito N, Hosaka M, Takeuchi T. Reactive oxygen species-mediated pancreatic $\{$ beta cell death is regulated by interactions between stressactivated protein kinases, p38 and c-Jun $\mathrm{N}$-terminal kinase and mitogen-activated protein kinase phosphatases. Endocrinology 2008; 149:1654-65.

26. Afanas'ev IB. Signaling mechanisms of oxygen and nitrogen free radicals CRC Press, Boca Raton USA 2009; 81-128.

27. Cao J, Xu D, Wang D, Wu R, Zhang L, Zhu H. ROS-driven Akt dephosphorylation at Ser- 473 is involved in 4-HPR-mediated apoptosis in NB4 cells. Free Radic Biol Med 2009; 47:536-47. 
28. Koya D, King GL. Protein kinase C activation and the development of diabetic complications. Diabetes 1998; 47:859-66.

29. Geolotto G, Papparella I, Lenzini L, Sartori M, Mazzoni $\mathrm{M}$, Iori $\mathrm{E}$, et al. Insulin generates free radicals in human fibroblasts ex vivo by a protein kinase C-dependent mechanism, which is inhibited by pravastatin. Free Radic Biol Med 2006; 41:473-83.

30. Lee HB, Yu MR, Song JS, Ha H. Reactive oxygen species amplify protein kinase $\mathrm{C}$ signaling in high glucose-induced fibronectin expression by human peritoneal mesothelial cells. Kidney Int 2004; 65:1170-9.

31. Xia L, Wang H, Munk S, Frecker H, Goldberg HJ, Fantus IG, Whiteside CI. Reactive oxygen species, PKC-beta1 and PKC-zeta mediate high-glucoseinduced vascular endothelial growth factor expression in mesangial cells. Am J Physiol Endocrinol Metab 2007; 293:1280-8.

32. Xia L, Wang H, Munk S, Kwan J, Goldberg HJ, Fantus IG, et al. High glucose activates PKC-zeta and NADPH oxidase through autocrine TGF-betal signaling in mesangial cells. Am J Physiol Renal Physiol 2008; 295:1705-14.

33. Lavrentyev EN, Malik KU. High glucose-induced Nox1-derived superoxides downregulate PKC- $\beta I I$, which subsequently decreases ACE2 expression and ANG(1-7) formation in rat VSMCs. Am J Physiol Heart Circ Physiol 2009; 296:106-18.

34. Ceolotto G, Bevilacqua M, Papparella I, Baritono E, Franco L, Corvaja C, et al. Insulin generates free radicals by an NAD $(\mathrm{P}) \mathrm{H}$, phosphatidylinositol 3'-kinasedependent mechanism in human skin fibroblasts ex vivo. Diabetes 2004; 53:1344-51.

35. Kinoshita H, Matsuda N, Kaba H, Hatakeyama N, Azma T, Nakahata K, et al. Roles of phosphatidylinositol 3-kinase-Akt and NADPH oxidase in adenosine 5'-triphosphate-sensitive $\mathrm{K}^{+}$channel function impaired by high glucose in the human artery. Hypertension 2008; 52:507-13.

36. Simone S, Gorin Y, Velagapudi C, Abboud HE, Habib SL. Mechanism of oxidative DNA damage in diabetes: tuberin inactivation and downregulation of DNA repair enzyme 8-oxo-7,8-dihydro-2'-deoxyguanosine-DNA glycosylase. Diabetes 2008; 57:2626-36.

37. Allen CL, Bayraktutan U. Antioxidants attenuate hyperglycaemia-mediated brain endothelial cell dysfunction and blood-brain barrier hyperpermeability. Diabetes Obes Metab 2009; 11:480-90.

38. Li Y, Descorbeth M, Anand-Srivastava MB. Role of oxidative stress in high glucose-induced decreased expression of Gi\{alpha\} proteins and adenylyl cyclase signaling in vascular smooth muscle cells. Am J Physiol Heart Circ Physiol 2008; 294:2845-54.

39. Shen E, Li Y, Li Y, Shan L, Zhu H, Feng Q, et al. $\mathrm{Racl}$ is required for cardiomyocyte apoptosis during hyperglycemia. Diabetes 2009; 58:2386-95.

40. Lin CL, Wang FS, Kuo YR, Huang YT, Huang HC, Sun YC, et al. Ras modulation of superoxide activates ERK-dependent fibronectin expression in diabetes-induced renal injuries. Kidney Int 2006; 69:1593-600.

41. Ceolotto G, Gallo A, Papparella I, Franco L, Murphy $\mathrm{E}$, Iori E, et al. Rosiglitazone reduces glucose-induced oxidative stress mediated by $\mathrm{NAD}(\mathrm{P}) \mathrm{H}$ oxidase via AMPK-dependent mechanism. Arterioscler Thromb Vasc Biol 2007; 27:2627-33.

42. Eid AA, Ford BM, Block K, Kasinath BS, Gorin Y, Ghosh Choudhury G, et al. AMPK negatively regulates NOX4-dependent activation of 53 and epithelial cell apoptosis in diabetes. J Biol Chem 2010; 285: 37503-12.

43. Pinton P, Rimessi A, Marchi S, Orsini F, Migliaccio E, Giorgio $M$, et al. Protein kinase $C ß$ and prolyl isomerase 1 regulate mitochondrial effects of the life-span determinant p66Shc. Science 2007; 315: 659-63.
44. Migliaccio E, Giorgio M, Mele S, Pelicci G, Reboldi $\mathrm{P}$, Pandolfi PP, et al. The p66shc adaptor protein controls oxidative stress response and life span in mammals. Nature 1999; 402:309-13.

45. Camici GG, Schiavoni M, Francia P, Bachschmid M, Martin-Padura I, Herssberger M, et al. Genetic deletion of p66(Shc) adaptor protein prevents hyperglycemia-induced endothelial dysfunction and oxidative stress. Proc Natl Acad Sci USA 2007; 104:5217-22.

46. Chintapalli J, Yang S, Opawumi D, Goyal SR, Shamsuddin N, Malhotra A, et al. Inhibition of wildtype p66ShcA in mesangial cells prevents glycooxidant-dependent FOXO3a regulation and promote the survival phenotype. Am J Physiol Renal Physiol 2007; 292:523-30.

47. Malhotra A, Vashistha H, Yadav VS, Dube MG Kalra SP, Abdellatif M, et al. Inhibition of p66ShcA redox activity in cardiac muscle cells attenuate hyperglycemia-induced oxidative stress and apoptosis. Am J Physiol Heart Circ Physiol 2009; 296:380-8.

48. Rota M, LeCapitaine N, Hosoda T, Boni A, De Angelis A, Padin-Iruegas ME, et al. Diabetes promotes cardiac stem cell aging and heart failure, which are prevented by deletion of the p66shc gene. Circ Res 2006; 99:42-52.

49. Kato M, Yuan H, Xu ZG, Lanting L, Li SL, Wang $\mathrm{M}$, et al. Role of the Akt/FoxO3a pathway in TGF \{beta\}1-mediated mesangial cell dysfunction: a novel mechanism related to diabetic kidney disease. J Am Soc Nephrol 2006; 17:3325-35.

50. Turdi S, Li Q, Lopes FL, Ren J. Catalase alleviates cardiomyocyte dysfunction in diabetes: role of Akt, Forkhead transcriptional factor and silent information regulator 2. Life Sci 2007; 81:895-905.

51. Davila D, Torres-Aleman I. Neuronal death by oxidative stress involves activation of $\mathrm{FOXO} 3$ through a two-arm pathway that activates stress kinases and attenuates insulin-like growth factor I signaling. Mol BiolCell 2008; 19:2014-25.

52. Cai W, He JC, Zhu L, Chen X, Striker GE, Vlassara H. AGE-receptor-1 counteracts cellular oxidant stress induced by AGEs via negative regulation of p66shcdependent FKHRL1 phosphorylation. Am J Physio Cell Physiol 2008; 294:145-52.

53. Hou J, Chong ZZ, Shang YC, Maiese K. FOXO3a governs early and late apoptotic endothelial programs during elevated glucose through mitochondrial and caspase signaling. Mol Cell Endocrinol 2010; 321:194-206

54. Maiese K, Chong ZZ, Shang YC. OutFOXOing disease and disability: the therapeutic potential of targeting FoxO proteins. Trends Mol Med 2008 14:219-27.

55. Maiese K, Hou J, Chong ZZ, Shang YC. A fork in the path: Developing therapeutic inroads with FoxO proteins. Oxid Med Cell Longev 2009; 2:119-29.

56. Maiese K, Chong ZZ, Hou J, Shang YC. Oxidative stress: Biomarkers and novel therapeutic pathways. Exp Gerontol 2010; 45:217-34.

57. Avogaro A, de Kreutzenberg SV, Fadini GP. Insulin signaling and life span. Pflugers Arch 2010; 459:301-14.

58. Barrett WC, DeGnore JP, Keng YF, Zhang ZY, Yim MB, Chock PB. Roles of superoxide radical anion in signal transduction mediated by reversible regulation of protein-tyrosine phosphatase 1B. J Biol Chem 1999; 274:34543-6.

59. Wang Q, Dube D, Friesen RW, LeRiche TG, Bateman KP, Trimble L, et al. Catalytic inactivation of proteinTyrosine phosphatase CD4 and protein tyrosine phosphatase $1 \mathrm{~B}$ by polyaromatic quinones. Biochemistry 2004; 43:4294-303.

60. Goldstein BJ, Mahadev K, Wu X. Insulin action is facilitated by insulin-stimulated reactive oxygen species with multiple potential signaling targets. Diabetes 2005; 54:311-21.
61. Wu X, Zhu L, Zilbering A, Mahadev K, Motoshima $\mathrm{H}$, Yao J, et al. Hyperglycemia potentiates $\mathrm{H}(2) \mathrm{O}(2)$ production in adipocytes and enhances insulin signal transduction: potential role for oxidative inhibition of thiol-sensitive protein-tyrosine phosphatases. Antioxid Redox Signal 2005; 7:526-37.

62. Droge W. Oxidative aging and insulin receptor signaling. J Gerontol A Biol Sci Med Sci 2005; 60:1378-85.

63. Meng TC, Buckley DA, Galic S, Tiganis T, Tonks NK. Regulation of insulin signaling through reversible oxidation of the protein-tyrosine phosphatases TC45 and PTP1B. J Biol Chem 2004; 279:37716-25.

64. Beyer TA, Xu W, Teupser D, Keller U, Bugnon P, Hildt E, et al. Impaired liver regeneration in Nrf2 knockout mice: role of ROS-mediated insulin/IGF-1 resistance. EMBO J 2008; 27:212-23.

65. Taniyama Y, Hitomi H, Shah A, Aleksander RW, Griendling KK. Mechanisms of reactive oxygen species-dependent downregulation of insulin receptor substrate-1 by Angiotensin II. Arterioscler Thromb Vasc Biol 2005; 25:1142-7.

66. Imoto K, Kukidome D, Nishikawa T, Matsuhisa T, Sonoda K, Fujisawa K, et al. Impact of mitochondrial reactive oxygen species and apoptosis signal-regulating kinase 1 on insulin signaling. Diabetes 2006; 55:1197-204

67. Nishikawa T, Kukidome D, Sonoda K, Fujisawa K, Matsuhisa T, Motoshima H, et al. Impact of mitochondrial ROS production in the pathogenesis of insulin resistance. Diabetes Res Clin Pract 2007; 77:161-4.

68. Sakai K, Matsumoto K, Nishikawa T, Suefuji M, Nakamaru K, Hirashima Y, et al. Mitochondrial reactive oxygen species reduce insulin secretion by pancreatic beta-cells. Biochem Biophys Res Commun 2003; 300:216-22.

69. Krauss S, Zhang CY, Scorrano L, Dalgaard LT, St-Pierre J, Grey ST, et al. Superoxide-mediated activation of uncoupling protein 2 causes pancreatic beta cell dysfunction. J Clin Invest 2003; 112:1831-42.

70. Pi J, Bai Y, Zhang Q, Wong V, Floering LM, Daniel $\mathrm{K}$, et al. Reactive oxygen species as a signal in glucose-stimulated insulin secretion. Diabetes 2007; 56:1783-91.

71. Li N, Brun T, Chop M, Cunha DA, Eizirik DL, Maechler P, et al. Transient exposure of $\beta$-cells to oxidative stress interrupts the transduction of signals normally coupling glucose metabolism to insulin secretion. J Biol Chem 2009; 284: 23602-12.

72. Fridlyand LE, Philipson LH. Does the glucosedependent insulin secretion mechanism itself cause oxidative stress in pancreatic ß-cells? Diabetes 2004; 53:1942-8.

73. Houstis N, ED Rosen ED, Lander ES. Reactive oxygen species have a causal role in multiple forms of insulin resistance. Nature 2006; 440:944-8.

74. Hoehn KL, Salmon AB, Hohnen-Behrens C, Turner $\mathrm{N}$, Hoy AJ, Maghzal GJ, et al. Insulin resistance is cellular antioxidant defense mechanism. Proc Natl Acad Sci USA 2009; 106:17787-92.

75. Nakamura S, Takamura T, Matsuzawa-Nagata N, Takayama H, Misu H, Noda $\mathrm{H}$, et al. Palmitate induces insulin resistance in H4IIEC3 hepatocytes through reactive oxygen species produced by mitochondria. J Biol Chem 2009; 284:14809-18.

76. Kumashiro N, Tamura Y, Uchida T, Ogihara T, Fujitani, Hirose T, et al. Impact of oxidative stress and peroxisome proliferator-activated receptor gamma coactivator-1alpha in hepatic insulin resistance. Diabetes 2008; 57:2083-91.

77. Ali MI, Ketsawatsomkron P, Berlin de Chantelemele EJ, Mintz JD, Muta K, Salet C, et al. Deletion of protein tyrosine phosphatase $1 \mathrm{~b}$ improves peripheral insulin resistance and vascular function in obese, leptin-resistant mice via reduced oxidant tone. Circ Res 2009; 105:1013-22. 
78. Langenstroer P, Pieper GM. Regulation of spontaneous EDRF release in diabetic rat aorta by oxygen free radicals. Am J Physiol 1999; 263:257-65.

79. Dixon LJ, Hughes SM, Rooney K, Madden A, Devine A, Leahey W, et al. Increased superoxide production in hypertensive patients with diabetes mellitus: role of nitric oxide synthase. Am J Hypertens 2005; 18:839-43.

80. Oak JH, Cai H. Attenuation of angiotensin II signaling recouples eNOS and inhibits nonendothelial NOX activity in diabetic mice. Diabetes 2007; 56:118-26.

81. Thum T, Fraccarollo D, Schultheiss M, Froese S, Galuppo P, Widder JD, et al. Endothelial nitric oxide synthase uncoupling impairs endothelial progenitor cell mobilization and function in diabetes. Diabetes 2007; 56:666-74.

82. Huang JS, Chuang LY, Guh JY, Huang YJ. Effects of nitric oxide and antioxidants on advanced glycation end products-induced hypertrophic growth in human renal tubular cells. Toxicol Sci 2009; 111:109-19.

83. Russo I, Del Mese P, Doronzo G, Mattiello L, Viretto $\mathrm{M}$, Bosia A, et al. Resistance to the nitric oxide/ cyclic guanosine 5'-monophosphate/protein kinase $\mathrm{G}$ pathway in vascular smooth muscle cells from the obese Zucker rat, a classical animal model of insulin resistance: role of oxidative stress. Endocrinology 2008; 149:1480-9.

84. Lin LY, Lin CY, Ho FM, Liau CS. Upregulation of the association between heat shock protein 90 and endothelial nitric oxide synthase prevents high glucose-induced apoptosis in human endothelial cells. J Cell Biochem 2005; 94:194-201.
85. Presely T, Vedam K, Druhan LJ, Ilangovan G. Hyperthermia-induced Hsp90/eNOS preserves mitochondrial respiration in hyperglycemic endothelial cells by downregulating Glut-1 and upregulating G6PD activity. J Biol Chem 2010; 10.1074/jbc. M110.147728.

86. Turan B. Role of antioxidants in redox regulation of diabetic cardiovascular complications. Curr Pharm Biotechnol 2010; 11:819-36.

87. Afanas'ev IB, Kuprianova NS, Polozova NI. Kinetics and mechanism of the reactions of the superoxide ion in solution. V. Kinetics and mechanism of the interaction of superoxide ion with vitamin $\mathrm{E}$ and ascorbic acid. J Chem Soc Perkin Trans 2 1987; 281-5.

88. Denisov ET, Afanas'ev IB. Oxidation and Antioxidants in Organic Chemistry and Biology. CRC Press: Boca Raton USA 2005; 29.

89. Ceolotto G, Papparella I, Lenzini L, Sartori M, Mazzoni M, Iori E, et al. Insulin generates free radicals in human fibroblasts ex vivo by a protein kinase C-dependent mechanism, which is inhibited by pravastatin. Free Radic Biol Med 2006; 41:473-83

90. Midaoui AE, Champlain J. Effects of glucose and insulin on the development of oxidative stress and hypertension in animal models of type 1 and type 2 diabetes. J Hypertens 2005; 23:581-8.

91. Schafer A, Vogt C, Fraccarollo D, Widder J, Flierl U, Hildemann SK, et al. Eplerenone improves vascular function and reduces platelet activation in diabetic rats. J Physiol Pharmacol 2010; 61:45-52.

92. Chacko B, Reily C, Srivastava A, Johnson MS, Ulasova E, Agarwal A, et al. Prevention of diabetic nephropathy inIns2 ${ }^{+/-}$AkitaJ mice by mitochondriatargeted therapy Mito Q. Biochem J 2010; 432:9-19.
93. Bulhak AA, Jung C, Ostenson CG, Lundberg JO, Sjoquist PO, Pernow J. PPAR- activation protect the type 2 diabetic myocardium against ischemiareperfusion injury: involvement of the PI3-Kinase/ Akt and NO pathway. Am J Physiol Heart Circ Physiol 2009; 296:719-27.

94. Minamiyama Y, Bito Y, Takemura S, Takahashi Y, Kodai S, Mizuguchi S, et al. Calorie restriction improves cardiovascular risk factors via reduction of mitochondrial reactive oxygen species in type II diabetic rats. J Pharmacol Exp Ther 2007; 320:535-43.

95. Willcox BJ, Donlon TA, He Q, et al. FOXO3A genotype is strongly associated with human longevity. Proc Natl Acad Sci USA 2008; 105:13987-92.

96. Hsu MF, Meng TC. Enhancement of insulin responsiveness by nitric oxide-mediated inactivation of protein-tyrosine phosphatases. J Biol Chem 2010; 285:7919-28.

97. Isoni CA, Borges EA, Veloso CA, Mattos RT, Chaves MM, Nogueira-Machado JA. cAMP activates the generation of reactive oxygen species and inhibits the secretion of IL-6 in peripheral blood mononuclea cells from type 2 diabetic patients. Oxid Med Cell Longev 2009; 2:317-21.

98. Chong ZZ, Shang YC, Hou J, Maiese K. Wntl neuroprotection translates into improved neurological function during oxidant stress and cerebral ischemia through AKT1 and mitochondrial apoptotic pathways. Oxid Med Cell Longev 2010; 3:153-65. 


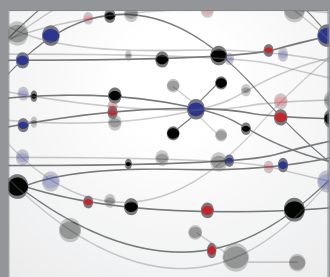

The Scientific World Journal
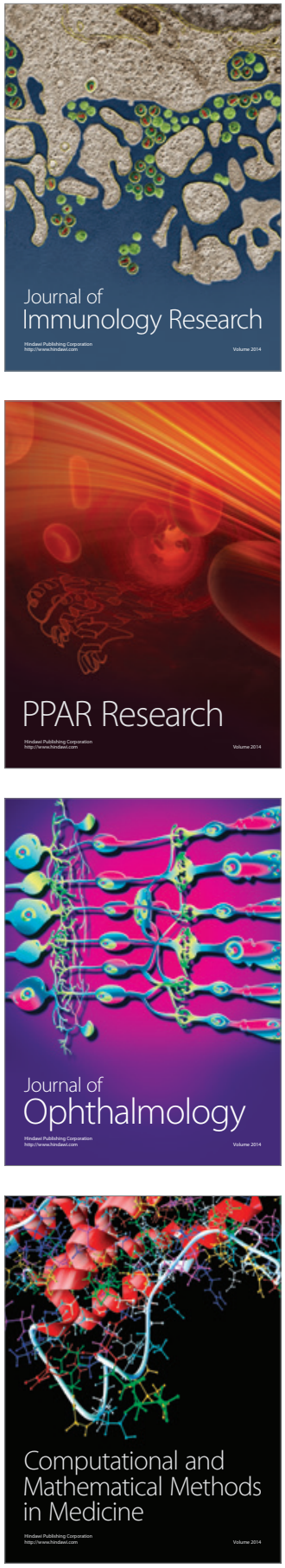

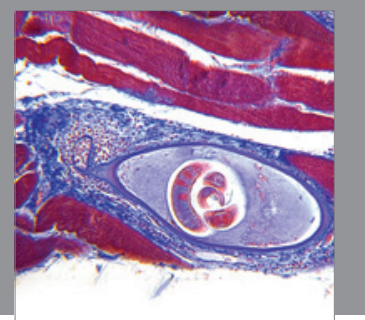

Gastroenterology

Research and Practice
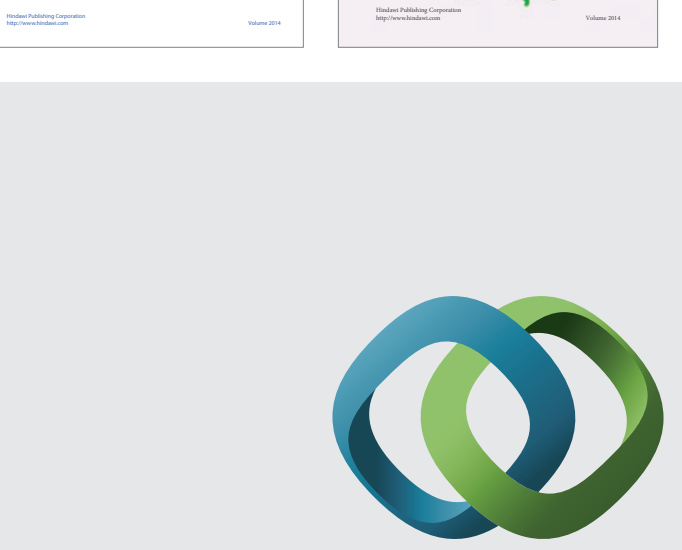

\section{Hindawi}

Submit your manuscripts at

http://www.hindawi.com
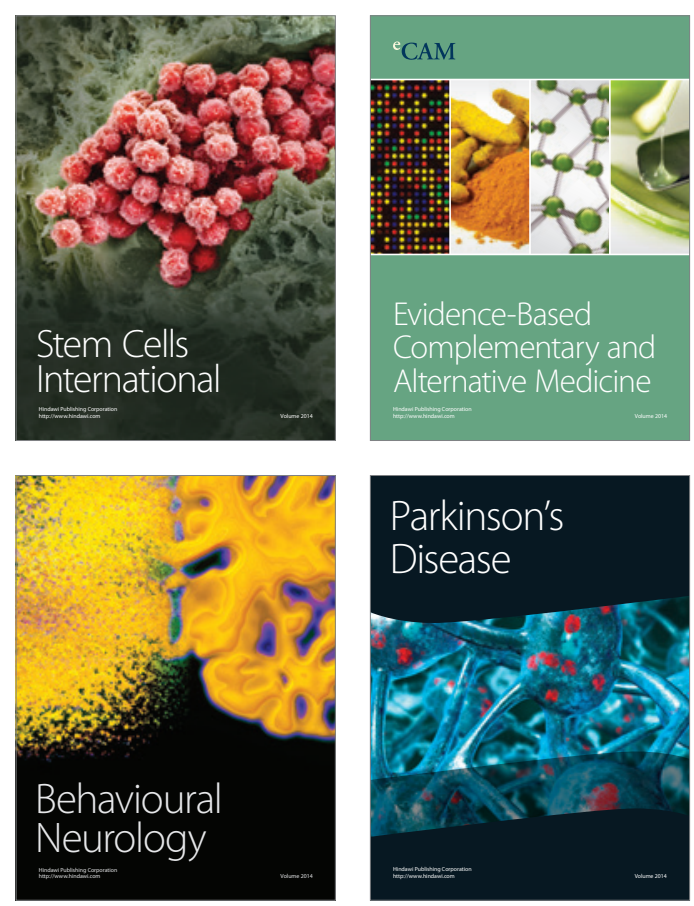

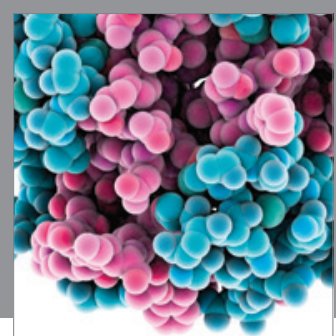

Journal of
Diabetes Research

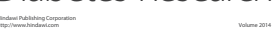

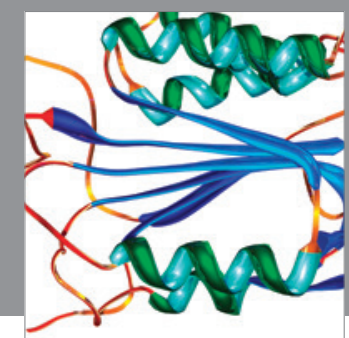

Disease Markers
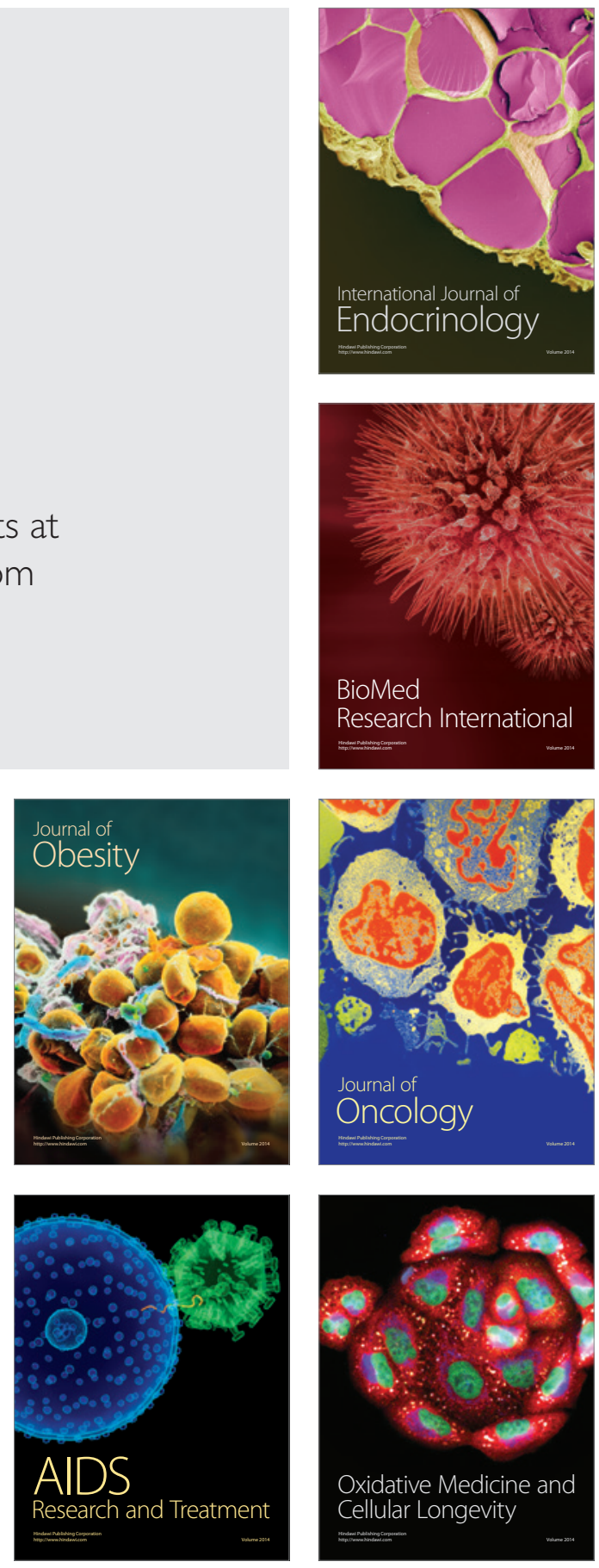